\title{
BƯớC ĐẦU ĐÁNH GIÁ KHẢ NĂNG SỦ̉ DỰG RFCC KHÔNG NGHIỀN LÀM PHỤ GIA TRONG SẢN XUẤT XI MĂNG
}

\author{
ĐỖ DOÃN DUNG, BÙI ĐĂNG HƯNG, NGUYỄN PHÚC THUỲ DƯƠNG, \\ TRẦ THỊ PHÚC NGÂN, LAI TRUNG QUỐC \\ Truờng Đại học Công nghiệp Thành phố Hồ Chi Minh; \\ dodoandung@iuh.edu.vn
}

Tóm tắt. Trong thời gian tới ở Việt Nam, khi có nhiều nhà máy lọc dầu đi vào hoạt động, sẽ có một lượng lớn xúc tác đã qua sử dụng- gọi tắt là "RFCC" sẽ được thải ra, đây sẽ là một thách thức trong công tác quản lý môi trường. Nghiên cứu này đánh giá khả năng tái sử dụng RFCC không nghiền (RFCC-KN) làm chất phụ gia cho các loại xi măng đang được sản xuất tại Việt Nam bao gồm OPC, PBC30, PBC40 và PCB50. Kết quả thu được cho thấy RFCC-KN có tính chất lý-hóa tương tự như tro bay, một loại chất phụ gia đang được sử dụng rộng rãi trong sản xuất xi măng. RFCC-KN có thể phối trộn ở các tỉ lệ khác nhau để tạo ra nhiều loại xi măng. Xi măng OPC có thể phối trộn với RFCC-KN với tỉ lệ khối lượng đến $30 \%$ để tạo PCB 40. Đối với các loại xi măng PCB, tỉ lệ thay thế của RFCC-KN là $20 \%$ và $10 \%$ tương ứng với PCB50 và $\mathrm{PCB} 30$. Và việc sử dụng RFCC-KN có thể giúp giảm chi phí sản xuất 1 tấn xi măng từ 6 đến $19 \%$.

Từ khóa. Cường độ chịu nén, phụ gia, RFCC, xi măng, xúc tác đã qua sử dụng.

\section{RESIDUE FLUID CATALYTIC CRACKING (RFCC) AS AN ALTERNATIVE ADDITIVE IN CEMENT PRODUCTION: A PRELIMINARY EVALUATION}

\begin{abstract}
In the upcoming time, there are many refineries that are under operation in Vietnam. As a result, a large amount of spent-RFCC catalyst will be discharged, and this will be a challenge for the environmental management. Our study aims at evaluating the reusability of non-grinded RFCC (RFCC-KN) as an additive for the different types of cement (OPC, PBC30, PBC40 and PCB50) manufacturing in Vietnam. The results show that RFCC-KN had the same physicochemical properties as fly ash - an additive widely used in current cement production. RFCC-KN was able to mix with cement at different mass ratios to produce many types of cement. OPC cement was mixed with RFCC-KN at a mass ratio up to $30 \%$ to make PCB40. For PCBs, the ratios of RFCC-KN in PCB50 and PCB30 were 20 and 10\%, respectively. In comparison with clinker, the use of RFCC-KN as an additive in cement production could reduce cost in the range of 6 $-19 \%$.
\end{abstract}

Keywords. Compressive strength, supplementary, RFCC, cement, spent catalyst.

\section{MỞ ĐẦU}

Với mong muốn tự chủ về năng lượng và giảm tỷ trọng kinh tế dựa vào việc xuất khẩu nguyên liệu thô như dầu mỏ, Việt Nam đã cấp phép đầu tư cho nhiều nhà máy lọc dầu trải dài trên lãnh thổ. Tuy nhiên, cả nước mới chỉ có nhà máy lọc hoá dầu Bình Sơn đang hoạt động ổn định với công suất trên 10.000 .000 triệu thùng dầu/năm. Trong quá trình hoạt động một lượng chất thải rắn công nghiệp đáng kể bị thải ra và yêu cầu phải có giải pháp xử lý và quản lý thích hợp. Trong số đó có xúc tác FCC bị mất hoạt tính (hay còn gọi là xúc tác qua sử dụng- gọi tắt là "RFCC") hàng năm được thải ra nhiều nhất. Khi hoạt động ổn định, trung bình mỗi ngày nhà máy thải ra từ 15- 20 tấn RFCC, thậm chí có ngày lên đến 25 tấn, tương đương với 6500- 8500 tấn RFCC cần phải được xử lý hàng năm. Hàng năm, nhà máy phải tiêu tốn một phần lợi nhuận kinh doanh cho công tác xử lý RFCC bằng biện pháp chôn lấp. Có thể thấy trước khi nhiều nhà máy lọc dầu đi vào hoạt động, ví dụ như nhà máy lọc dầu Nghi Sơn dự kiến sẽ đi vào hoạt động trong năm 2018 với công suất gấp 3 lần nhà máy lọc dầu Bình Sơn [6], lượng RFCC thải bỏ sẽ rất lớn, đòi hỏi chi phí cao để xử lý theo quy định.

Hiện nay, việc tái sử dụng RFCC đã được triển khai thương mại hóa trên thế giới như sử dụng RFCC như nguyên liệu sản xuất xi măng tại nhà máy Boral (Úc), Holcim (Mỹ) [3], và đây là ứng dụng phổ biến nhất của RFCC. Tại Oman, RFCC thải ra tại nhà máy lọc dầu Sohar Refinery có kích thước rất mịn được 
trộn sống làm phụ gia khoáng trong sản xuất xi măng với tỉ lệ phối trộn $0,5-5 \%$ khối lượng và phối trộn này dùng để sản xuất gạch đất sét nung; trong khí đó, RFCC từ nhà máy Mina $\mathrm{Al}-\mathrm{Fahal}$ có kích thước hạt lớn hơn $2 \mathrm{~mm}$ được thử nghiệm sử dụng như cốt liệu thô [9].

Tại Việt Nam, cũng có những đề tài nghiên cứu liên quan đến đến việc tái sử dụng RFCC từ nhà máy Bình Sơn nhằm giúp tiết kiệm phần kinh phí xử lý môi trường cũng như tận dụng lại nguồn nguyên liệu. Đề tài Bộ Khoa học Công nghệ (mã số 11395/2015) [21] tập trung vào quy trình khôi phục hoạt tính xúc tác RFCC thải sử dụng cho các quá trình cracking dầu nhờn thải, tuy nhiên chỉ dừng ở quy mô nhỏ chưa phát triển thành công nghệ. Hay đề tài hợp tác giữa trường Đại học Huế và Công ty $\mathrm{CP}$ Cơ-Điện-Môi trường Lilama phát triển quy trình sản xuất gạch không nung, tuy nhiển sản phẩm không tiêu thụ được [4], [11]. Nhà máy cũng đã cấp kinh phí cho Viện Dầu khí nghiên cứu khả năng sử dụng chất xúc tác RFCC đã qua giai đoạn nghiền (RFCC-N) làm phụ gia xi măng với tỉ lệ phối trộn lên tới $15 \%$ xúc tác RFCC. Kết quả được đánh giá rất khả quan khi giá trị cường độ chịu nén của hỗn hợp giữa RFCC được nghiền mịn và xi măng $\mathrm{OPC}$ cao hơn giá trị cường độ chịu nén của mẫu trắng, đạt được cường độ chịu nén theo tiêu chuẩn, và khả năng chịu nén của mẫu vữa có xu hướng tăng khi tăng hàm lượng RFCC đã nghiền (tuy nhiên không quá 15\%) [12]. Để tiết kiệm chi phí, cần đánh giá thêm cách tận dụng RFCC không nghiền trước (RFCC$\mathrm{KN}$ ) vào quá trình sản xuất xi măng. Bên cạnh đó đề tài của Nguyễn Thị Châm [12] chỉ mới quan tâm đến ảnh hưởng của RFCC đã nghiền với xi măng $\mathrm{OPC}$ với tỷ lệ phối trộn nhỏ hơn $15 \%$ nên cần nghiên cứu thêm sự ảnh hưởng của RFCC-KN với xi măng $\mathrm{OPC}$ với tỷ lệ phối trộn $>15 \%$, và đánh giá khả năng phối trộn xúc tác RFCC-KN với các loại xi măng PCB để sản xuất xi măng. Đây là hướng đi đầu tiên ở Việt Nam. Nghiên cứu đánh giá khả năng sử dụng RFCC- KN là chất phụ gia trong xi măng được thực hiện theo khung nghiên cứu như Hình 1.

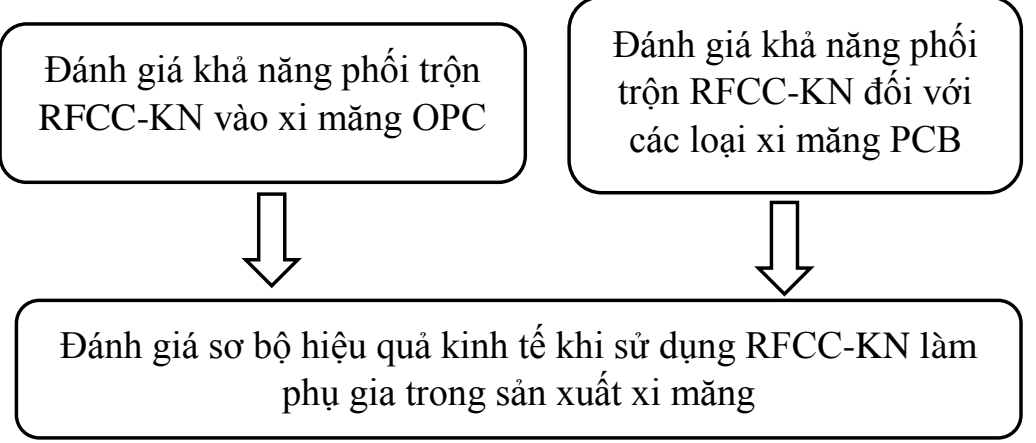

Hình 1. Khung nghiên cứu đánh giá khả năng sử dụng RFCC-KN là chất phụ gia xi măng

\section{VậT LIỆU VÀ PHƯƠNG PHÁP NGHIÊN CƯU}

Để giải quyết được các nội dung trên, nhóm nghiên cứu đã tiến hành các thực nghiệm với các vật liệu thí nghiệm và phương pháp được trình bày trong phần này.

\subsection{Vật liệu nghiên cứu}

Các vật liệu được sử dụng bao gồm xi măng (OPC, PBC50, $\mathrm{PCB} 40$ và $\mathrm{PCB} 30)$ và phụ gia (RFCC và tro bay). Trong đó tro bay được sử dụng là đối tượng so sánh vì vật liệu thải này đang được sử dụng làm chất phụ gia sản xuất xi măng.

\subsubsection{Xi măng:}

Các loại xi măng sau được sử dụng trong quá trình nghiên cứu:

- Xi măng OPC được sản xuất từ quá trình nghiền clinke xi măng Fico-Tây Ninh với 4\% thạch cao. Cường độ chịu nén của xi măng $\mathrm{OPC}$ sử dụng trong thí nghiệm đạt theo tiêu chuẩn TCVN 2682-2009 dành cho xi măng PC50.

- Xi măng PCB50, PCB40 đang được sản xuất và thương mại hoá tại nhà máy xi măng Fico-Nhà Bè và $\mathrm{PCB} 30$ đang được sản xuất tại nhà máy Fico-Bình Dương. Tính chất của các loại xi măng đạt theo tiêu chuẩn TCVN 6260-2009. 


\subsubsection{RFCC:}

Hiện nay, duy nhất có nhà máy lọc dầu Bình Sơn đã đi vào hoạt động và lượng RFCC thải ra hàng ngày cũng ổn định. Theo yêu cầu cơ bản của tận dụng chất thải công nghiệp, chất thải công nghiệp không nguy hại mới có thể được phép sử dụng. Và theo giấy phép đăng ký quản lý nguồn thải, RFCC thải ra tại phân xưởng Craking (như hình 2a) phải được đốt cốc ở nhiệt độ $1200^{\circ} \mathrm{C}$ để loại bỏ hoàn toàn chất hữu cơ trước khi được thải bỏ hoàn toàn. Vì thế, RFCC đã trải qua giai đoạn đốt cháy carbon (như hình $2 \mathrm{~b}$ ) được sử dụng trong nghiên cứu này.

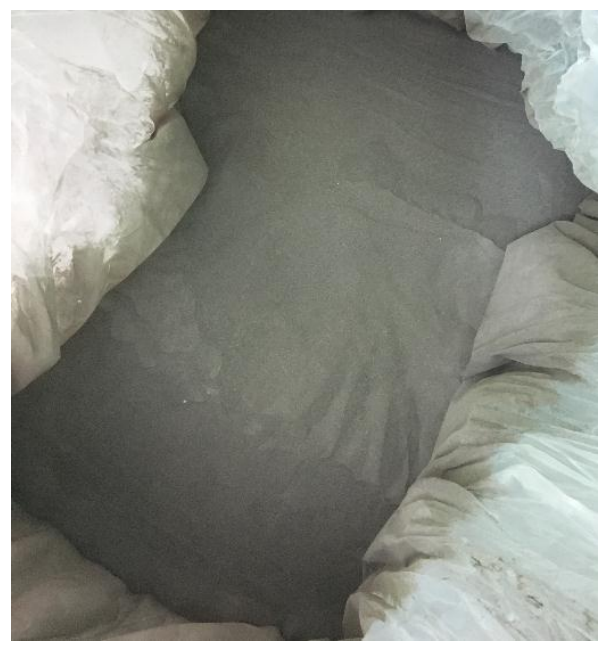

(a)

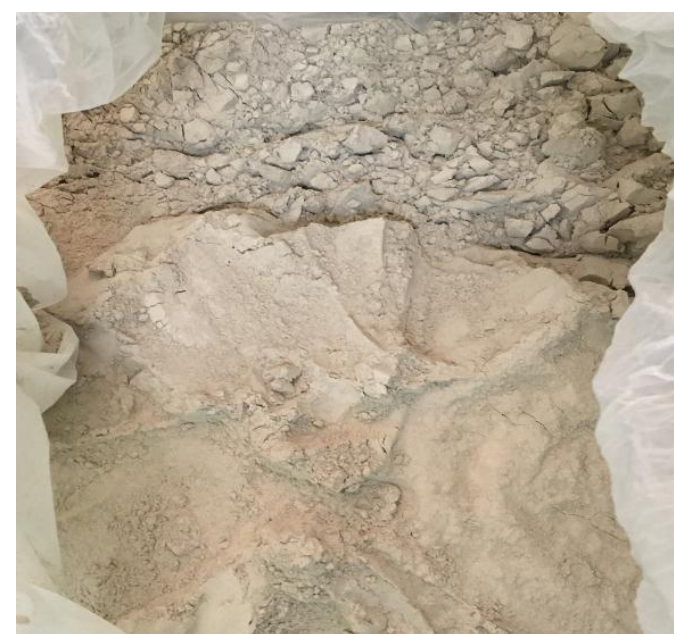

(b)

Hình 2. Bột RFCC từ nhà máy lọc dầu Bình Sơn được sử dụng trong nghiên cứu

(a) sau khi cracking, (b) sau khi đốt cháy carbon

\subsubsection{Tro bay:}

Tro bay được sử dụng để so sánh lấy từ nhà máy nhiệt điện Duyên Hải 3 (Hình 3). Tro bay này có màu vàng đậm. Theo thông tin từ nhà máy Fico-Nhà Bè, tro bay từ nhà máy nhiệt điện Duyên Hải 3 hoàn toàn phù hợp để làm phụ gia cho quá trình sản xuất xi măng Portland hỗn hợp.

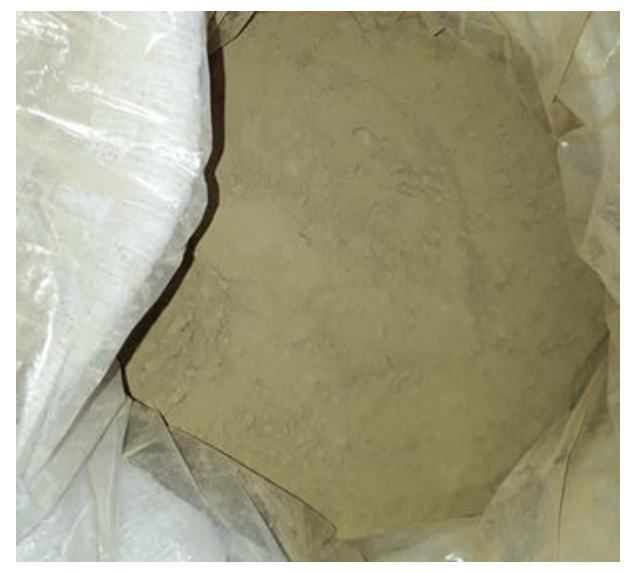

Hình 3. Bột tro bay sử dụng trong sản xuất xi măng tại nhà máy Fico - Nhà Bè - Tro bay Duyên Hải 3 sử dụng trong nghiên cứu 


\subsection{Phương pháp nghiên cứu}

\subsubsection{Phân tích các tính chất vật lý và hóa học của RFCC-KN và so sánh với tro bay:}

Để đánh giá khả năng ứng dụng RFCC-KN từ nhà máy lọc dầu Bình Sơn làm phụ gia cho xi măng, các mẫu RFCC-KN được gửi đến phòng thí nghiệm nhà máy xi măng Fico để phân tích thành phần hoá học theo TCVN 141:1998 và thành phần hạt theo TCVN 7572-2:2006. Kết quả sẽ được so sánh với kết quả phân tích đối với phụ gia tro bay của nhà máy nhiệt điện Duyên Hải. Thành phần hoá học của tro bay cũng được phân tích theo TCVN 141:1998.

\subsubsection{Phuơng pháp đúc mẫu xi măng và phân tích cường độ chịu nén của mẫu:}

Việc nghiên cứu ảnh hưởng của RFCC-KN đến cường độ chịu nén của các loại xi măng được thực hiện theo sơ đồ Hình 4.

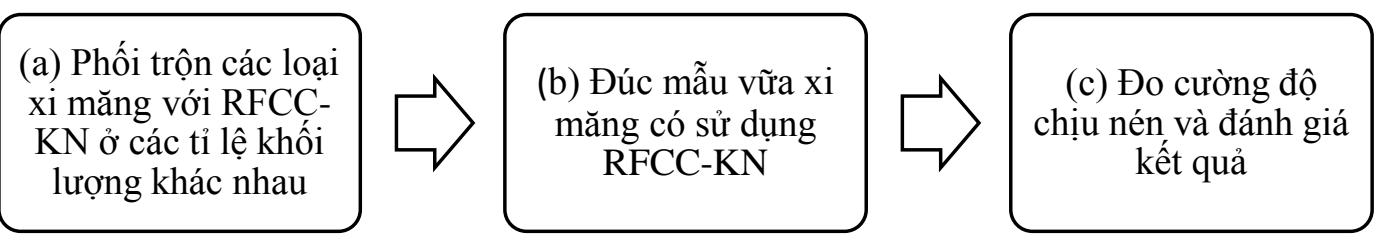

Hình 4. Các bước tiến hành để đánh giá ảnh hưởng của RFCC-KN khi phối trộn với các loại xi măng

a. Phối trộn các loại xi măng với RFCC-KN

Theo nghiên cứu của Nguyễn Thị Châm [12], khả năng chịu nén có xu hướng tăng khi tăng hàm lượng RFCC đã nghiền nhưng chỉ mới dừng ở lệ $15 \%$, vì thế các thí nghiệm đối với loại xi măng OPC với tỷ lệ thay thế xi măng bằng RFCC-KN được thực hiện ở các tỷ lệ $0 \%, 10 \%, 15 \%, 20 \%, 25 \%$, và $30 \%$ (theo khối lượng).

Theo tiêu chuẩn TCVN 6260:2009 dành cho xi măng Portland hỗn hợp, tổng lượng phụ gia khoáng (không kể thạch cao) không được lớn hơn $40 \%$, vì thế tuỳ theo loại xi măng PCB thì tỷ lệ phối trộn RFCC$\mathrm{KN}$ trong thực nghiệm thay đổi cụ thể như sau:

- PCB30: tỷ lệ thay thế RFCC-KN được thực hiện ở các tỉ lệ $0 \%, 10 \%, 15 \%$, và $20 \%$.

- PCB40: tỷ lệ thay thế RFCC-KN được thực hiện ở các tỉ lệ $0 \%, 15 \%, 20 \%$, và $25 \%$.

- PCB50: tỷ lệ thay thế RFCC-KN được thực hiện ở các tỉ lệ $0 \%, 15 \%, 20 \%, 30 \%$, và $40 \%$

(Tỷ lệ phối trộn đối với các loại PCB khác nhau như trên được chọn theo sự tư vấn của phòng Quản lý Chất lượng của nhà máy xi măng Fico-Nhà Bè để tiết kiệm thời gian và chi phí làm thực nghiệm)

b. Đúc mẫu vữa xi măng đã phối trộn

Ban đầu, mẫu được đúc sơ bộ theo phương pháp TCVN 6016-2011 (Hình 5) với tỷ lệ phối trộn với RFCC-KN là $20 \%$ và $30 \%$. Kết quả ban đầu cho thấy mẫu sau khi đúc xong khô nhanh, lý do là RFCC là vật liệu rất háu nước. Do đó, hỗn hợp vữa thu được khô và khó đổ khuôn. Mẫu sau khi tháo khuôn không được bằng phẳng và gây sai số lớn cho kết quả kiểm tra cường độ nén. Để đảm bảo độ chính xác cao hơn, phương pháp test mẫu theo ASTMC109/C109M-16A được lựa chọn thay thế cho phương TCVN6016-2011 và đây cũng là phương pháp đúc mẫu đã được sử dụng trong nghiên cứu trước. Với phương pháp đúc mẫu theo ATSM, độ chảy của các mẫu đều đồng nhất. Mẫu dễ đổ khuôn và bề mặt láng hơn so với mẫu đúc sơ bộ (Hình 6a). Độ chảy được duy trì suốt quá trình thực nghiệm là $160 \mathrm{~mm}$ như hình $6 \mathrm{~b}$.

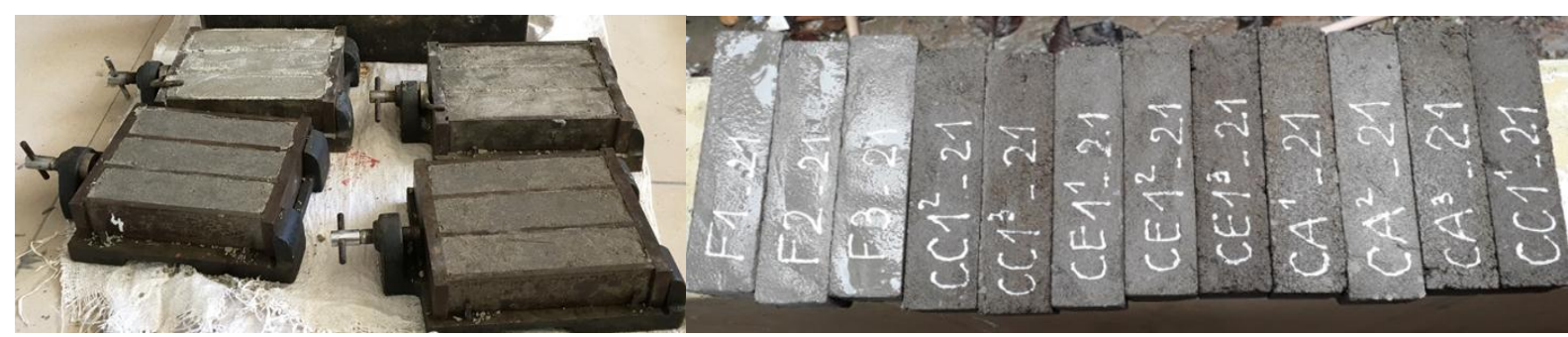

Hình 5. Mẫu sơ bộ khi đổ khuôn và tháo khuôn theo TCVN6016-2011 


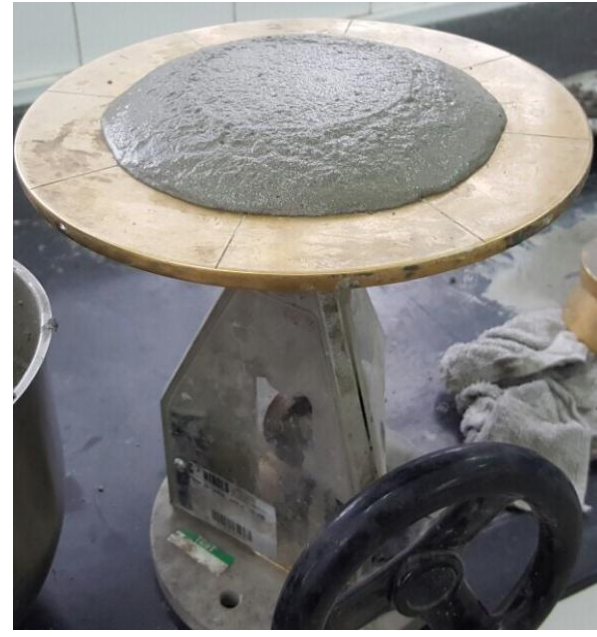

(a)

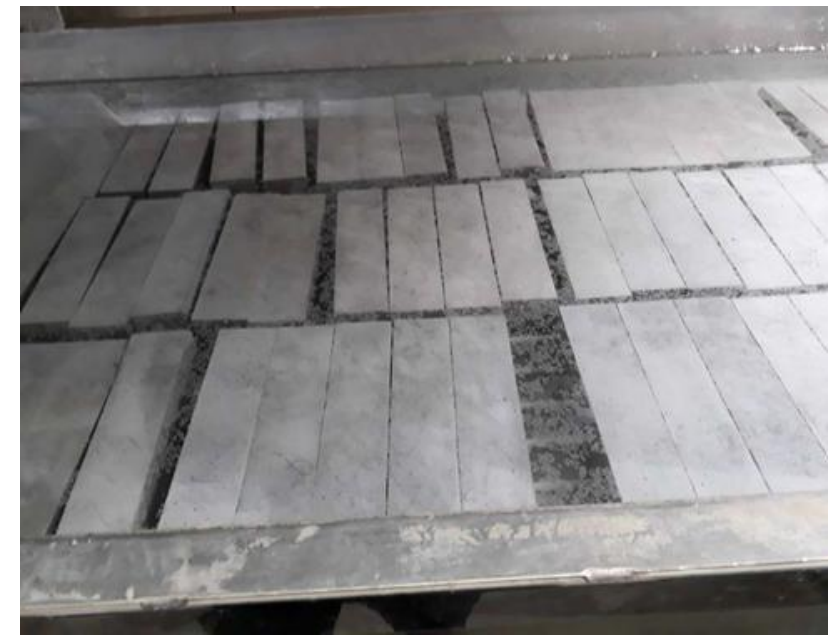

(b)

Hình 6. Mẫu đúc theo ASTM C109:99

(a) Độ chảy của vữa (d 160mm) (b) Mẫu sau khi tháo khuôn

c. Kiểm tra cường độ chịu nén của các mẫu đúc

Các mẫu sau khi đúc được bảo dưỡng ở các khoảng thời gian 3 ngày và 28 ngày. Đối với mỗi tỉ lệ ở các thời gian dưỡng mẫu khác nhau, có 4 mẫu được chuẩn bị tương ứng và được đo cường độ chịu nén của mẫu bằng các thiết bị chuyên dụng tại nhà máy xi măng Fico-Nhà Bè.

Kết quả đo sẽ được đánh giá dựa vào so sánh với mẫu đối chứng (mẫu $0 \%$ ) bằng phương pháp phân tích thống kê $95 \%$ LSD (sử dụng phần mềm Stratgraphics). Ngoài ra, kết quả đo sẽ được so sánh với tro bay thu thập được từ những thực nghiệm của nhà máy xi măng Fico-Nhà Bè.

\subsubsection{So sánh chi phí sản xuất sơ bộ}

Việc đánh giá tính kính tế chỉ dừng lại ở mức sơ bộ bằng cách so sánh chi phí vật liệu khi thay thế RFCC-KN cho các chất phụ gia khác hoặc thay thế clinker trong sản xuất các loại xi măng thương phẩm hiện có của nhà máy xi măng Fico- Nhà Bè, gồm : Xi măng xá (PCB50) và xi măng bao (PCB40).

Cơ sở tính toán chi phí dựa vào giá nguyên liệu theo "Định mức sản xuất 2016" do phòng Kế hoạch Vật tư của nhà máy Xi măng Fico - Nhà Bè lập vào ngày 01/12/2015 [13], cụ thể như trình bày trong bảng 1 .

Bảng 1 . Giá thành các vật liệu sử dụng để sản xuất xi măng*

\begin{tabular}{|c|c|c|c|c|}
\hline & \multicolumn{4}{|c|}{ Nguyên liệu rắn } \\
\hline \multirow{2}{*}{$\begin{array}{c}\text { Giá thành } \\
(V N D / \text { tấn })\end{array}$} & Clinker & Thạch cao & Đá vôi & Puzolan \\
\cline { 2 - 5 } & 1.054 .073 & 672.727 & 210.000 & 140.000 \\
\hline
\end{tabular}

Đối với RFCC-KN, đây là chất thải công nghiệp không nguy hại chưa được thương mại hoá nên giá thành hiện tại là 0 đồng. Bên cạnh đó nếu việc tận dụng RFCC-KN thành công, nhà máy có thể có thêm kinh phí được chi trả từ nhà máy lọc dầu. Tuy nhiên đánh giá này không bao gồm khoản thu thêm này vì chưa có số liệu.

\section{KẾT QUẢ VÀ THẢO LUẬN}

\subsection{Thành phần, tính chất của xúc tác RFCC-KN của nhà máy Lọc dầu Bình Sơn và tro bay Duyên Hải}

\subsubsection{Thành phần hạt của RFCC-KN:}

\footnotetext{
*Nguồn: Phòng Kế hoạch Vật tư- Nhà máy Fico, Nhà Bè [13]
} 
Bảng 3 thể hiện kết quả phân tích thành phần hạt tự nhiên của RFCC-KN theo phương pháp thử TCVN 7572-2:2006. Kết quả cho thấy rằng không có hạt nào lớn hơn kích thước $0,075 \mathrm{~mm}$, phù hợp với độ mịn theo tiêu chuẩn cho phép của xi măng Portland theo TCVN 2682-2009 với quy định phần còn lại trên sàng kích thước lỗ 0,09 mm không lớn hơn 10\%. Bên cạnh đó, độ ẩm của RFCC-KN thấp hơn 1\%, nhỏ hơn độ ẩm cho phép của phụ gia tro bay được sử dụng trong xi măng theo TCVN 10302-2014.

Với kết quả về thành phần hạt, độ ẩm cho thấy rằng RFCC-KN của nhà máy lọc dầu Bình Sơn có khả năng phối trộn với xi măng mà không cần qua giai đoạn gia công sấy ẩm hay nghiền.

Bảng 2. Thành phần hạt của RFCC-KN thải từ nhà máy lọc dầu Bình Sơn

\begin{tabular}{|l|c|c|}
\hline \multicolumn{1}{|c|}{ Chỉ tiêu } & Kết quả & Phuong pháp thỉ \\
\hline Thành phần hạt (lượng lọt sàng qua các cỡ sàng & & TCVN 7572-2: 2006 \\
mắt vuông) (\%) & $100 \%$ & \\
$0,600 \mathrm{~mm}$ & $100 \%$ & \\
$0,300 \mathrm{~mm}$ & $100 \%$ & \\
$0,075 \mathrm{~mm}$ & $<1,00$ & TCVN 7572-7: 2006 \\
\hline Độ ẩm $(\%)$ & & \\
\hline
\end{tabular}

Nguồn: Kết quả phân tích mẫu được thưc hiện tại phòng thí nghiệm trọng điểm đường bộ III, Tp. HCM

\subsubsection{Thành phần hóa hoc của RFCC-KN:}

Kết quả phân tích thu được (bảng 4) cho thấy, RFCC-KN thải ra từ nhà máy lọc dầu Bình Sơn chủ yếu chứa $\mathrm{SiO}_{2}, \mathrm{Al}_{2} \mathrm{O}_{3}, \mathrm{Fe}_{2} \mathrm{O}_{3}$ (chiếm trên 92,37\%), cao hơn hàm lượng tổng $\mathrm{SiO}_{2}, \mathrm{Al}_{2} \mathrm{O}_{3}, \mathrm{Fe}_{2} \mathrm{O}_{3}$ (chiếm trên $78,24 \%$ ) của tro bay Duyên Hải 3 .

Bảng 3. Thành phần hoá học của RFCC-KN, tro bay Duyên Hải 3 (\% khối lượng), theo tiêu chuẩn TCVN 141:1998

\begin{tabular}{|c|c|c|c|c|c|c|c|c|c|}
\hline \multirow{2}{*}{ Chỉ tiêu } & \multicolumn{7}{|c|}{ Thành phần hóa học (\%) } \\
\cline { 2 - 10 } & $\mathbf{C K T}$ & $\mathrm{SO}_{3}$ & $\mathbf{M K N}$ & $\mathrm{Al}_{2} \mathrm{O}_{3}$ & $\mathrm{Fe}_{2} \mathrm{O}_{3}$ & $\mathbf{C a O}$ & $\mathbf{M g O}$ & $\mathrm{SiO}_{2}$ & $\mathrm{CaO}_{\boldsymbol{t d}}$ \\
\hline $\begin{array}{c}\text { Tro bay } \\
\text { Duyên Hải 3 }\end{array}$ & 58,76 & 0,13 & 4,28 & 23,76 & 12,02 & 0,78 & 0,44 & 42,46 & 0,02 \\
\hline RFCC-KN & 59,08 & - & 4,18 & 47,5 & 0,65 & 0,379 & 1,19 & 44,22 & - \\
\hline
\end{tabular}

Ghi chú: “- " không phát hiện

\subsubsection{Tính độc hại:}

Một yếu tố quan trọng của việc tận dụng lại chất thải công nghiệp làm phụ gia xi măng là phải đảm bảo về tiêu chí hoạt động phóng xạ tự nhiên. Theo Nguyễn Thị Ngọc Châm và các cộng sự, RFCC của nhà máy lọc dầu Bình Sơn có hoạt tính phóng xạ $\left(\mathrm{A}_{\mathrm{eff}}=331,3 \mathrm{~Bq} / \mathrm{kg}\right)$ thấp hơn mức tiêu chuẩn quy định (370 $B q / k g$, theo TCVN 10302-2014). Cũng theo tác giả này, nếu đánh giá cho $100 \%$ chất xúc tác RFCC khi sử dụng 40\% làm phụ gia cho xi măng (hàm lượng phụ gia tối đa cho phép theo TCVN 6260:2009), thì nồng độ các kim loại nặng vẫn nằm trong ngưỡng cho phép theo QCVN 07:2009/BTNMT.

\subsection{Kết quả thực nghiệm cường độ của cường độ của hỗn hợp vữa RFCC-KN và so sánh với tro bay Duyên Hải 3}

Kết quả đo cường độ chịu nén của các mẫu ở thời gian gian dưỡng 3 ngày và 28 ngày được thể hiện trong hình 7.

\subsubsection{Xi măng OPC:}


Có thể thấy cường độ chịu nén đối với các mẫu dưỡng 3 ngày giảm khi gia tăng tỷ lệ phối trộn RFCCKN (Hình 7 (a)). Phân tích thống kê 95\% LSD cho thấy các giá trị ở các tỉ lệ phối trộn đều khác nhau đáng kể $(P<0.05)$.

Đối với các mẫu dưỡng 28 ngày, khả năng chịu nén gia tăng từ 2 đến 3 lần so với mẫu dưỡng 3 ngày. Hình 7 (a) cho thấy khi tăng tỷ lệ phối trộn RFCC-KN đến $15 \%$ thì cường độ chịu nén có sự gia tăng so với mẫu đối chứng. Ở tỉ lệ phối trộn $20 \%$, mặc dù cường độ chịu nén giảm so với tỉ lệ 10 và $15 \%$ nhưng vẫn tương đương với mẫu đối chứng. Khi gia tăng đến $25 \%$ và $30 \%$ cường độ chịu nén giảm đáng kể so với mẫu đối chứng.

Khi so sánh với TCVN 6260:2009 về xi măng Portland hỗn hợp, tất cả mẫu có RFCC-KN trộn với xi măng OPC theo các tỷ lệ khối lượng đều đạt tiêu chuẩn. Cụ thể, mẫu chứa RFCC dưới $20 \%$ đạt tiêu chuẩn dành cho xi măng PCB50, mẫu chứa 25 và $30 \%$ RFCC thì đạt tiêu chuẩn dành cho xi măng PCB 40.

\subsubsection{Các loại xi măng PCB:}

Nhìn chung đối với tất cả các loại xi măng PCB, sau 3 ngày dưỡng mẫu thu được có cường độ chịu nén giảm khi gia tăng tỉ lệ khối lượng RFCC-KN phối trộn, các giá trị đều khác biệt đáng kể về mặt thống kê (Hình 7 (b), (c) và (d)). Các kết quả thu thập được đối với phu gia tro bay cũng thể hiện đặc điểm này. Sau 3 ngày dưỡng, cường độ chịu nén đối với mẫu có sử dụng phụ gia tro bay cao hơn so với mẫu có sử dụng RFCC-KN (Phụ lục 1).

Trong trường hợp dưỡng sau 28 ngày, cường độ chịu nén gia tăng từ 1,5 đến 2 lần so với dưỡng 3 ngày, và sự thay đổi khi thay đổi tỉ lệ khối lượng RFCC-KN phối trộn có sự khác nhau ở các loại PCB.

Đối với PCB30, khả năng chịu nén của mẫu 28 ngày khi phối trộn RFCC-KN ở tỷ lệ $10 \%$ cao hơn so với mẫu chuẩn, tuy nhiên đến tỉ lệ lớn hơn $15 \%$ thì giảm thấp hơn so với mẫu chuẩn (khác biệt đáng kể về thống kê theo phương pháp 95\% LSD với $P<0.05$ ) (Hình 7 (b)). Khi so sánh với các số liệu tro bay thu được (Phụ lục 1a) cường độ chịu nén sau 28 ngày dưỡng khi sử dụng RFCC-KN làm phụ gia có giá trị cao hơn ở các tỷ lệ tương ứng.

Đối với PCB40, nhìn chung khả năng chịu nén của mẫu vữa có xu thế giảm khi tăng tỷ lệ phối trộn RFCC-KN (Hình 7 (c)). So với mẫu sử dụng tro bay so với mẫu đối chứng khả năng chịu nén của mẫu có sử dụng RFCC giảm ít hơn (phụ lục 1).

Đối với PCB50, cường độ chịu nén sau 28 ngày dưỡng cao so với mẫu chuẩn ở các mẫu phối trộn đến tỉ lệ $20 \%(P<0.05)$ (Hình 7 (d)). So với các kết quả sử dụng tro bay, có sự khác biệt rõ rệt khi cường độ nén 28 ngày của mẫu chứa RFCC đều lớn hơn ở tất cả các tỷ lệ tương ứng (Phụ lục1).

So sánh giữa các loại $\mathrm{PCB}$ khi phối trộn với RFCC-KN, ta nhận thấy rằng cường độ chịu nén 28 ngày của mẫu $\mathrm{PCB} 30$ với $10 \%$ RFCC-KN và cường độ chịu nén 28 ngày của $\mathrm{PCB} 50$ với $15 \%$ RFCC-KN cao hơn mẫu chuẩn. Trong khi đó, cường độ chịu nén 28 ngày của mẫu PCB40 với $15 \%$ RFCC-KN thấp hơn so với mẫu chuẩn. Nguyên nhân có sự khác biệt này là do nhà máy xi măng Fico- Nhà Bè đang sử dụng các phụ gia hoá học: Phu gia SES của GRACE và GM1 189 của Phan Hà Gia [13] nhằm giúp tăng cường độ và giảm thời gian ninh kết cho xi măng $\mathrm{PCB} 40$. Xi măng có sử dụng các loại phụ gia này yêu cầu ít nước nhưng RFCC-KN có tính hút nước mạnh, nên mẫu vữa thu được của các mẫu PCB40 khi có phối trộn RFCC-KN khô hơn mẫu chuẩn. Vì thế, cường độ chịu nén khi tăng tỷ lệ phối trộn RFCC-KN giảm hơn so với mẫu chuẩn. 

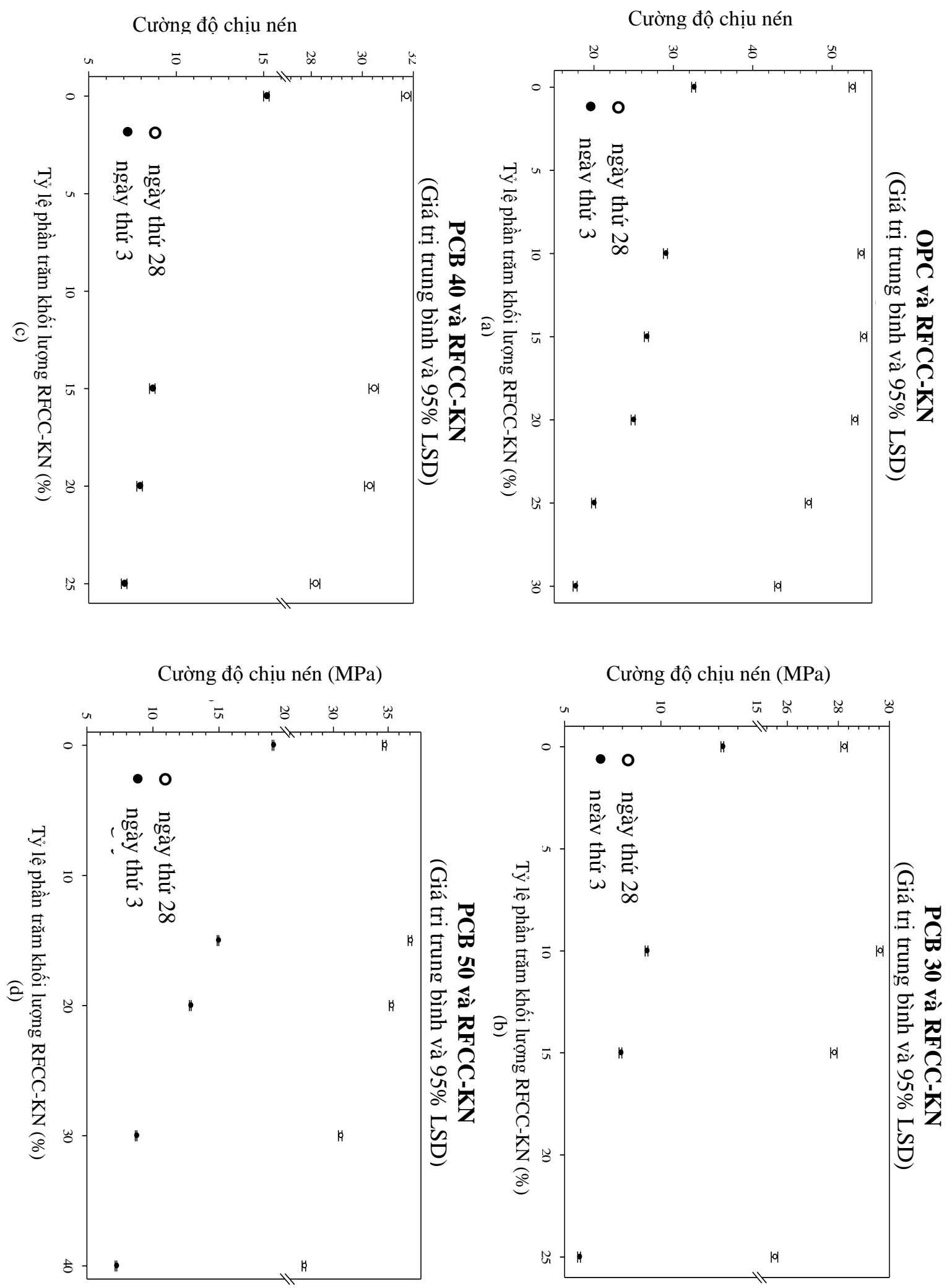

Hình 7: Cưòng độ chịu nén của hôn hợp xi măng và RFCC với các tỉ lệ phối trộn RFCC khác nhau ở các thời gian duõng 3 ngày và 28 ngày 


\subsection{Phân tích sơ bộ tính kinh tế}

Với giá thành nguyên liệu sản xuất xi măng trong phần 2.4, và tỉ lệ cấp phối đối với các loại xi măng được cung cấp bởi phòng Quản lý Chất lượng của nhà máy xi măng Fico- Nhà Bè, giá thành sơ bộ trên 1 tấn xi măng sản xuất được xác định trong bảng 5 .

Bảng 4. Tỉ lệ cấp phối các loại xi măng $(\mathrm{XM})$ và giá thành sản xuât sơ bộ tính theo nguyên vật liệu

\begin{tabular}{|c|c|c|c|c|c|c|}
\hline \multicolumn{4}{|c|}{$\begin{array}{c}\text { Tỉ lệ cấp phối } \\
\text { (\% theo khối lượng) }\end{array}$} & \multirow{2}{*}{$\begin{array}{c}\text { RFCC- } \\
\text { KN } \\
(k g / t \text { tân } X M)\end{array}$} & \multirow{2}{*}{$\begin{array}{l}\text { Giá thành } \\
(\text { d/ tấn XM) }\end{array}$} & \multirow{2}{*}{ Ghi chú } \\
\hline Clinker & Thạch cao & Đá vôi & Puzolan & & & \\
\hline \multicolumn{7}{|c|}{ Xi măng xá (PCB50) } \\
\hline 86 & 5 & 1,8 & 7,2 & 0,0 & 953.999 & Mẫu trắng \\
\hline 96 & 4 & 0 & 0 & 200 & 865.682 & $\begin{array}{l}\text { PCB } 50 \text { từ xi } \\
\text { măng OPC }\end{array}$ \\
\hline 68,8 & 5 & 1,8 & 7,2 & 200 & 772.699 & $\begin{array}{l}\text { RFCC-KN thay } \\
\text { thế clinker }\end{array}$ \\
\hline \multicolumn{7}{|c|}{ Xi măng bao (PCB40) } \\
\hline 75 & 4,5 & 0 & 20,5 & 0 & 849527 & Mẫu trắng \\
\hline 96 & 4 & 0 & 0 & 300 & 799.092 & $\begin{array}{l}\text { PCB } 40 \text { từ xi } \\
\text { măng OPC }\end{array}$ \\
\hline 63,75 & 4,5 & 0 & 20,5 & 150 & 730.944 & $\begin{array}{l}\text { RFCC-KN thay } \\
\text { thế clinker }\end{array}$ \\
\hline
\end{tabular}

So với cấp phối đang sử dụng để sản xuất xi măng xá và xi măng bao tại nhà máy, cấp phối sản xuất xi măng thương phẩm từ xi măng $\mathrm{OPC}$ thu được từ nghiên cứu này có tỷ lệ clinker cao hơn. Tuy nhiên giá thành sản xuất xi măng xá cũng như xi măng bao khi sử dụng RFCC-KN phối trộn trực tiếp với xi măng OPC vẫn thấp hơn giá thành sản xuất hiện tại của nhà máy. Chí phí sản xuất tiết kiệm được khoảng $9 \%$ đối với $\mathrm{PCB} 50$ và $6 \%$ đối với $\mathrm{PCB} 40$.

Khi sử dụng RFCC-KN để thay thế clinker trong quá trình sản xuất xi măng, giá thành sản xuất xi măng xà và xi măng bao thấp hơn rất nhiều so với giá thành sản xuất theo cấp phối truyền thống. Chi phí sản xuất tiết kiệm được khoảng 19\% đối với xi măng PCB50 và 13.96\% PCB40.

\section{KẾT LUẬN}

Kết quả nghiên cứu cho thấy xúc tác đã qua sử dụng của nhà máy lọc dầu Bình Sơn "RFCC" có khả năng được tận dụng vào quá trình sản xuất xi măng mà không yêu cầu phải nghiền RFCC trước khi sử dụng. Tuỳ theo nhu cầu sử dụng, RFCC-KN có thể được phối trộn với nhiều tỷ lệ khác nhau để sản xuất ra nhiều loại xi măng. Theo kết quả thu được từ các thí nghiệm cho thấy đối với xi măng OPC tỉ lệ phối trộn có thể lên đến $30 \%$ đến tạo ra PCB40. Cần thêm những đánh giá đối với OPC ở mức tỉ lệ phối trộn RFCC lớn hơn $30 \%$ nhằm gia tăng sự thay thể trong sản xuất $\mathrm{PCB} 40$ và $\mathrm{PCB} 30$. Còn đối với các loại xi măng $\mathrm{PCB}$, tỉ lệ thay thế của RFCC-KN là $20 \%$ và $10 \%$ tương ứng với $\mathrm{PCB} 50$ và $\mathrm{PCB} 30$. So với tro bay, RFCC$\mathrm{KN}$ thể hiện khả năng tốt hơn về cường độ chịu nén cho sản phẩm thu được. Và việc sử dụng RFCC-KN có thể giúp giảm chi phí sản xuất 1 tấn xi măng từ 6-9\% hoặc 13.96-19\% tuỳ theo loại xi măng yêu cầu.

Tóm lại, RFCC-KN có thể được sử dụng cho việc sản xuất bê tông xi măng vì giá thành rẻ, độ mịn và cường độ mẫu vữa thu được đạt yêu cầu. Bên cạnh tro bay đang được sử dụng phổ biển, RFCC có tiềm năng là phụ gia khoáng chất lượng tốt cho sản xuất các loại xi măng khác nhau và có tiềm năng được sử dụng trong việc sản xuất các loại bê tông có sử dụng xi măng. Việc phát triển cường độ muộn của hỗn hợp vữa xi măng ở 28 ngày cho thấy tiềm năng nghiên cứu sâu hơn việc sử dụng RFCC làm phụ gia cho việc sản xuất xi măng bền sulfat. 


\section{LỜI CÁM ƠN}

Nghiên cứu được thực hiện dưới sự hỗ trợ về tài chính của quỹ nghiên cứu khoa học, trường Đại học Công nghiệp Thành phố Hồ Chí Minh theo Đề tài mã số 171.4011- Hợp đồng số 36/HĐ-ĐHCN. Chúng tôi xin cám ơn trường Đại học Công nghiệp Thành phố Hồ Chí Minh đã cấp kinh phí cho việc thực hiện đề tài và công ty xi măng Fico-Nhà Bè đã hỗ trợ về mặt kĩ thuật cho nghiên cứu. Bên cạnh đó, xín chân thành cám ơn những chuyên gia, đồng nghiệp đã hỗ trợ và đóng góp ý kiến quý giá trong quá trình thực hiện nghiên cứu này.

\section{TÀI LIỆU THAM KHẢO}

[1] B. Pacewska, I. Wilińska, J. Kubissa, Use of spent catalyst from catalytic cracking in fluidized bed as a new concrete additive, Thermochimica acta 322, page175-181, 1998.

[2] Global Hydroprocessing Catalyst (HPC) Market: An Analysis.

[3] H.-L. Chen, Y.-S. Tseng, K.-C. Hsu, Spent FCC catalyst as a pozzolanic material for high-performance mortars, Cement and Concrete Composites 26, page 657-664, 2004.

[4] Hồ Mạnh Hùng, Nghiên cứu tận dụng chất thải FCC tù Nhà máy lọc dầu Dung Quất để sản xuất gạch không nung, Luận văn Thạc sĩ khoa học Hóa học, Đại học Huế, 2012.

[5] I.A. (IGNAT), C.I. KONCSAG, Experimental study for the design of asphalt mixtures by recovering fcc spent catalysts, Romanian Chemical Engineering Society Bulletin 1, 2014.

[6] JGC Japan Company, Hồ sơ thiết kế Khu liên hợp lọc dầu Nghi Sơn - Thanh Hoá , 2008.

[7] J. Monzó, J. Payá, M. Borrachero, E. Mora, S. Velázquez, Fluid Catalytic Cracking Residue (FC3R) as a New Pozzolanic Material: Thermal Analysis Monitoring of FC3R/Portland Cement Reactions, Seventh CANMET, ACI., International Conference on Fly Ash, Silica Fume, Slag and Natural Pozzolans in Concrete, Suplementary papers, India, page 22-27, 2001.

[8] K. Alshamsi, M. Baawain, K. Aljabri, R. Taha, Z. Al-kamyani, Utilizing Waste Spent Catalyst in Asphalt Mixtures, Procedia - Social and Behavioral Sciences 53, page 326-334, 2012.

[9] M. Marafi, A. Stanislaus, E. Furimsky, Handbook of spent hydroprocessing catalysts: regeneration, rejuvenation, reclamation, environment and safety, Elsevier, 2010.

[10] M. Marafi, M. Rana, Refinery waste: the spent hydroprocessing catalyst and its recycling options, WIT Transactions on Ecology and the Environment 202, page 219-230, 2016.

[11] Nguyễn Phi Hùng, Đặng Văn Sỹ, Trần Quang Hữu, Nguyễn Hữu Hạnh, Hồ Mạnh Hùng, Nghiên cúu chế tạo gạch không nung tù xúc tác FCC đã qua sủ dụng của Nhà máy lọc dầu Dung Quất, Tạp chí Xúc tác và Hấp phụ, ISSN 0866-7411, Hội Xúc tác và Hấp phụ Việt Nam, tr. 107-112, 2013.

[12] Nguyễn Thị Châm, Nguyễn Mạnh Hà, Tạ Quang Minh, Nghiên cứu khả năng sủ dụng chất xúc tác RFCC qua sủ dụng của Nhà máy lọc dầu Qung Quất làm phu gia xi măng, Tạp chí PetroVietnam, trang 43-49, số 11/2013, 2013.

[13] Phòng Kế hoạch Vật tư- Nhà máy xi măng Fico, Nhà Bè, Định mức sản xuất năm 2016, T12/2015.

[14] QCVN 07 : 2009/BTNMT - Quy chuẩn kỹ thuật quốc gia về nguõng chất nguy hại.

[15] TCVN 10302 : 2014 - Phu gia hoạt tính tro bay dùng cho bê tông, vũa xây và xi măng.

[16] TCVN 141:1998 - Xi măng - Phuoong pháp phân tích hoá học.

[17] TCVN 2682 : 2009 - Xi măng Poóc Lăng - Yêu cầu kỹ thuạt. 
[18] TCVN 6016 : 2011 - Xi măng - Phuoong pháp thủ - Xác định độ bền.

[19] TCVN 6260 : 2009 - Xi măng Poóc Lăng hỗn hợp - Yêu cầu kỹ thuật.

[20] TCVN 7572- 2 : 2006 - Cốt liệu cho bê tông và vữa - Phương pháp thử - Phần 2: Xác định thành phần hạt.

[21] Trần Thị Như Mai, Nghiên cứu công nghệ phục hồi xúc tác FCC đã qua sủ dụng làm xúc tác cho quá trình cracking để chuyển hóa chất thải hữu co thành nhiên liệu và các quá trình lọc hóa dầu khác, Bộ Khoa học Công nghệ, 2015.

Ngày nhận bài: 05/3/2018

Ngày chấp nhận đăng: 28/4/2018 